\title{
Chitosan-silver oxide nanocomposite film: Preparation and antimicrobial activity
}

\author{
SHIPRA TRIPATHI, G K MEHROTRA and P K DUTTA* \\ Department of Chemistry, Motilal Nehru National Institute of Technology, Allahabad 211 004, India
}

MS received 7 July 2010; revised 31 October 2010

\begin{abstract}
The chitosan-silver oxide encapsulated nanocomposite film was prepared by solution casting method. The prepared film was characterized by FTIR, scanning electron microscopy (SEM), thermal studies, and UV-Vis spectroscopy. The elemental composition of the film was studied by energy dispersive X-ray analysis (EDAX). The antibacterial activity of the composite film against pathogenic bacteria viz. Escherichia coli, Staphylococcus aureus, Bacillus subtilis and Pseudomonas aeruginosa was measured by agar diffusion method. Our observations suggest that chitosan as biomaterial based nanocomposite film containing silver oxide has an excellent antibacterial ability for food packaging applications.
\end{abstract}

Keywords. Chitosan; silver oxide; nanocomposite; antibacterial; film; food packaging.

\section{Introduction}

Antimicrobial enhanced packaging films have great potential for ensuring the safety of foods through controlled release of antimicrobial substances from the carrier film structure to food surface. Recently, antimicrobial packaging has emerged as one of the most reliable and promising tool in the search for the next generation of 'active' packaging (Salleh et al 2007). It is well known that silver ions and silver-based compounds are highly toxic to microorganisms (Zhao and Stevens 1998) showing strong biocidal effects on as many as 16 species of bacteria including E. coli (Spadaro et al 1974). Thus, silver ions, as an antibacterial component, have been used in the formulation of dental resin composites (Yoshida et al 1999; Herrera et al 2001), ion exchange fibres (Nonaka et al 2000) and in coatings of medical devices (Schierholz et al 1999). The possible use of silver nanoparticles (AgNPs) as antibacterial agent has, therefore, been investigated as a means of arresting increasing bacterial resistance to conventional bactericides and antibiotics (Gogoi et al 2006). Numerous approaches have been used to prepare AgNPs for a rapidly growing list of catalysis, electronics, non-linear optics, and biomaterial applications (Nigam et al 2009). For example, laser ablation (Dolgaev et al 2002) and inert gas condensation techniques (Turker 2004) have been used to prepare silver nanopowders. A large variety of chemical processes are involved in the preparation of AgNPs with a well-controlled size.

Different types of nanomaterials like copper, zinc, titanium (Retchkiman-Schabes et al 2006), magnesium, gold (Gu et al 2003), alginate (Ahmad et al 2006) and silver have

*Author for correspondence (pkd_437@yahoo.com) come up but AgNPs have proved to be most effective as they have good antimicrobial efficacy against a wide variety of bacteria, viruses and other eukaryotic micro-organisms (Gong et al 2007). AgNPs used as drug disinfectant have some risks as the exposure to silver can cause agyrosis and argyria also; it is toxic to mammalian cells (Gong et al 2007).

Chitosan is the second most plentiful natural biopolymer and is relatively cheap (Dutta et al 2004). It has attracted considerable interest due to its biological properties, such as antimicrobial activity, antitumor activity, and immune enhancing effect. However, the antibacterial activity of chitosan is influenced by a number of factors, including the species of bacteria, concentration, $\mathrm{pH}$, solvent and molecular mass (Hernández-Lauzardo et al 2008). The proposed mechanism for its antimicrobial action is binding to the negatively charged bacterial cell wall, with consequent destabilization of the cell envelope and altered permeability, followed by attachment to DNA with inhibition of its replication (Helander et al 2001). Due to excellent antimicrobial property, chitosan film may be used in food packaging (Tripathi et al 2008a, 2009a,b; Dutta et al 2009). Recently, a chitosan-starch film has been prepared by using microwave treatment which may find potential application in food packaging (Tripathi et al 2008b). The recent review on antimicrobial and antioxidative activities of chitosans in food (Friedman and Juneja 2010) also expresses the hopefulness of the different findings of the researchers for further progress to improve microbial food safety and food quality.

In this communication, we report the synthesis of chitosan-silver oxide nanocomposite film via solution casting method. The ultimate objective was to study the antibacterial activity of the nanocomposite film. The nanocomposite film showed significant antibacterial activity against 
Escherichia coli, Staphylococcus aureus, Bacillus subtilis and Pseudomonas aeruginosa. The film was characterized by FTIR, TGA, SEM and EDAX analyses. The prepared method is an easy and processable one and the obtained data may be useful for food packaging applications.

\section{Experimental}

\subsection{Materials}

Chitosan (79\% deacetylated) was obtained from the Central Institute of Fisheries Technology (CIFT, Cochin). Acetic acid and tri-sodium citrate were obtained from CDH. Silver nitrate was obtained from Thomas Baker. The test strains, Escherichia coli MTCC 1303, Staphylococcus aureus, ATCC 6538, Bacillus subtilis ATCC 6633, and Pseudomonas aeruginosa MTCC 2453 were procured from IMTECH, Chandigarh.

\subsection{Preparation of chitosan-silver oxide nanocomposite film}

The silver-oxide nanoparticles were prepared by sodium citrate reduction of $\mathrm{AgNO}_{3}$ (Jin and Dong 2003). After the addition of trisodium citrate $(1 \% \mathrm{w} / \mathrm{v})$ into $\mathrm{AgNO}_{3}$ solution, black precipitates were obtained. The precipitates were filtered and rinsed with distilled water. The precipitates were then dispersed in distilled water. The prepared silver oxide sol $(1 \mathrm{~mL})$ was added into the chitosan solution $(1 \% \mathrm{w} / \mathrm{v}$ in $1 \%$ acetic acid) and stirred for $2 \mathrm{~h}$. The mixture solution was cast onto glass plates and dried at room temperature for $48 \mathrm{~h}$ to obtain the composite film.

\subsection{Characterizations}

The infrared spectra were recorded on Perkin Elmer RX1 FTIR spectrophotometer model. UV-Vis spectrum of the chitosan-silver oxide nanocomposite film was recorded on 1650PC UV spectrometer by tapping the film in the UVVis spectroscopy cell. Thermal degradation processes were investigated using TGA (Perkin Elmer Pyris 6) at a heating rate of $5{ }^{\circ} \mathrm{C}$ under Ar atmosphere. The morphology of the chitosan-silver oxide nanocomposite film was examined by a scanning electron microscopy (JEOL, Model JSM-6390LV) after gold coating.

\section{Results and discussion}

\section{$3.1 U V$-vis spectrum}

The UV-vis spectrum of chitosan- $\mathrm{Ag}_{2} \mathrm{O}$ nanocomposite film is shown in figure 1. A single peak at $425 \mathrm{~nm}$ in the spectrum of the composites arises due to the excitation of surface plasmon vibrations of $\mathrm{Ag}$ atoms.

\subsection{Fourier transform infrared spectroscopy (FTIR)}

The infrared spectra of chitosan and chitosan based silver oxide nanocomposite film are shown in figure 2. For chitosan spectrum (figure 2a), the characteristic peaks assignment of chitosan are $3429 \mathrm{~cm}^{-1}(\mathrm{O}-\mathrm{H}$ stretch overlapped with $\mathrm{N}-$ $\mathrm{H}$ stretch), 2921 and $2867 \mathrm{~cm}^{-1}$ (C-H stretch), $1640 \mathrm{~cm}^{-1}$ (amide II band, C-O stretch of acetyl group), $1592 \mathrm{~cm}^{-1}$ (amide II band, N-H stretch), 1485-1380 cm $\mathrm{cm}^{-1}$ (asymmetric $\mathrm{C}-\mathrm{H}$ bending of $\mathrm{CH}_{2}$ group) and $1087 \mathrm{~cm}^{-1}$ (skeletal vibration involving the bridge $\mathrm{C}-\mathrm{O}$ stretch) of glucosamine residue. While for the chitosan based silver oxide nanocomposite film (figure $2 \mathrm{~b}$ ), the spectral band appears at $3418 \mathrm{~cm}^{-1}$ (axial O-H group of chitosan), 2918 and

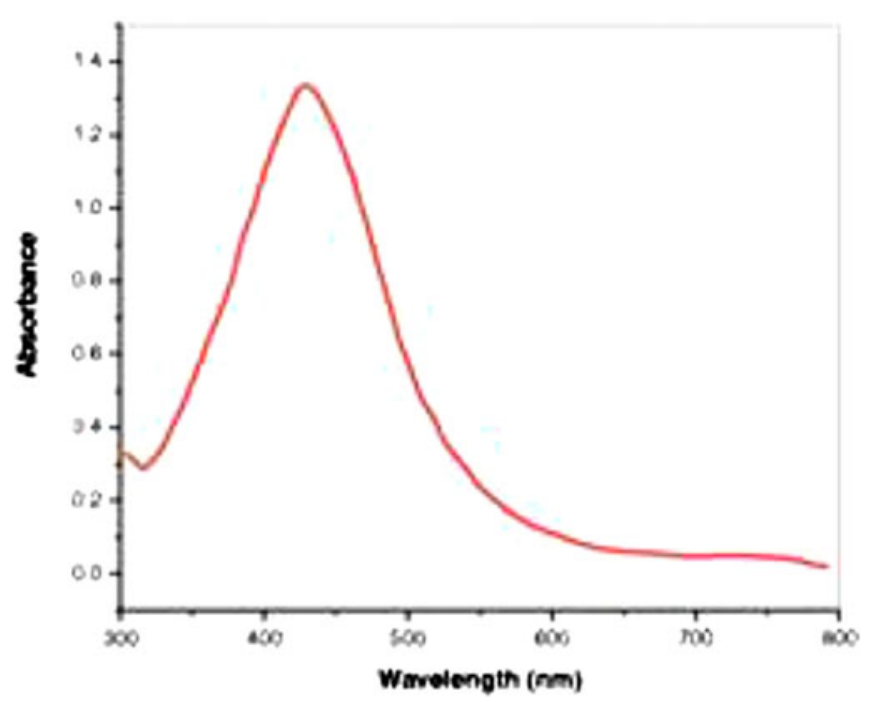

Figure 1. UV-visible spectrum of chitosan- $\mathrm{Ag}_{2} \mathrm{O}$ nanocomposite film (in tapping mode).

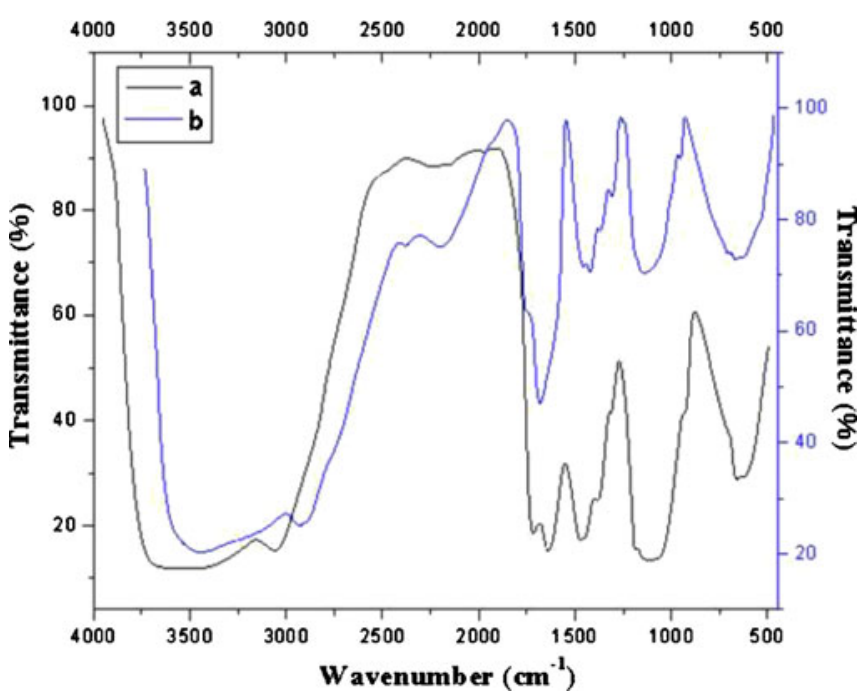

Figure 2. FTIR spectra of (a) chitosan, and (b) chitosan- $\mathrm{Ag}_{2} \mathrm{O}$ nanocomposite film. 


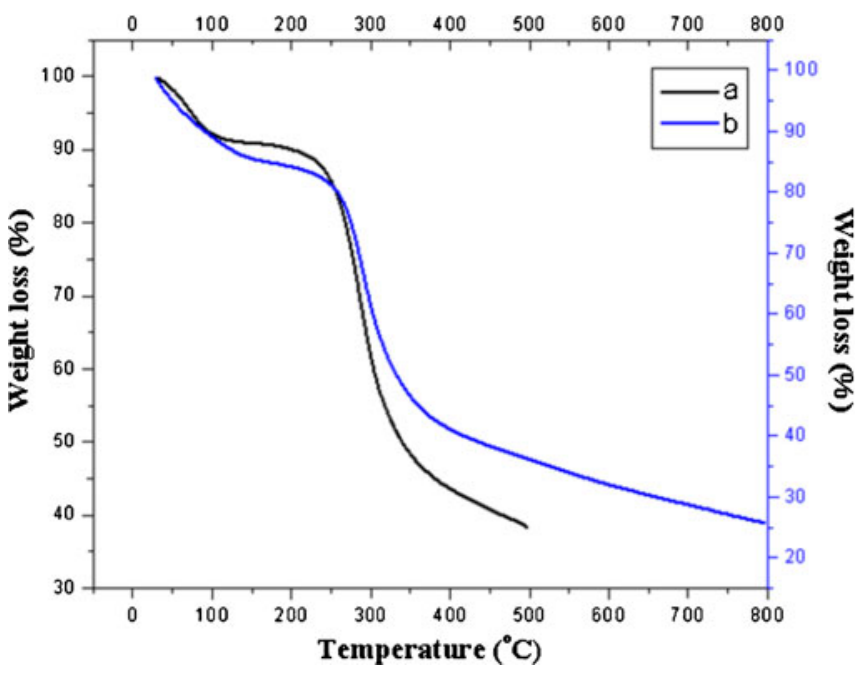

Figure 3. TGA thermograms of (a) chitosan, and (b) chitosan$\mathrm{Ag}_{2} \mathrm{O}$ nanocomposite film.

2837 (symmetric or asymmetric $\mathrm{CH}_{3}$ stretching vibration attributed to pyranose ring of chitosan), $2154 \mathrm{~cm}^{-1}(\mathrm{C}-\mathrm{N}$ asymmetric band stretching), $1621 \mathrm{~cm}^{-1}(\mathrm{C}=\mathrm{O}$ carbonyl group vibration), $1381 \mathrm{~cm}^{-1}(\mathrm{C}-\mathrm{C}$ stretching vibration and asymmetric $\mathrm{C}-\mathrm{H}$ bending of $\mathrm{CH}_{2}$ group), $1262-1109 \mathrm{~cm}^{-1}$ (skeletal vibration involving the bridge $\mathrm{C}-\mathrm{O}$ stretch) of glucosamine residue whereas the bands around 615 and $437 \mathrm{~cm}^{-1}$ are ascribable to intrinsic stretching vibrations of the metal-oxygen bond.

The FTIR analysis suggests that the prepared chitosan silver nanocomposite film consists of an intermediate/or complex of tri-ammonium citrate, chitosan and metal ions.

\subsection{Thermogravimetric analysis}

Thermal degradation of the chitosan and chitosan- $\mathrm{Ag}_{2} \mathrm{O}$ nanocomposite film is shown in figure 3 . Two weight losses are observed in the chitosan TGA curve (figure $3 a$ ). The weight loss at $50-150{ }^{\circ} \mathrm{C}$ is due to the moisture vaporization. The other weight loss at $200-300{ }^{\circ} \mathrm{C}$ is due to the degradation of chitosan molecule. In the TGA curve of the chitosan- $\mathrm{Ag}_{2} \mathrm{O}$ nanocomposite film too two weight losses are noticeable (figure $3 \mathrm{~b}$ ). The weight loss at $70-150{ }^{\circ} \mathrm{C}$ is due to the moisture vaporization. The other weight loss at 200$310^{\circ} \mathrm{C}$ is due to the degradation of chitosan and silver oxide molecule. This result shows the slight change in thermal stability of the nanocomposite film as compared to the chitosan alone due to presence of silver in the composite film.

\subsection{Morphological characterization}

Scanning electron microscopy (SEM) was used to investigate the surface morphology of chitosan- $\mathrm{Ag}_{2} \mathrm{O}$ nanocomposite film with reference to chitosan film and silver oxide nanoparticles. The SEM pictures of chitosan, silver oxide and chitosan- $\mathrm{Ag}_{2} \mathrm{O}$ nanocomposite film are shown in figure 4 . The chitosan- $\mathrm{Ag}_{2} \mathrm{O}$ nanocomposite film has aggregated particle structures (figure 4c), however, the micrographs of chitosan, and silver oxide (figures $4 \mathrm{a}$ and $\mathrm{b}$ ) are uniform. The particles in nanocomposite film were found with almost spherical morphology. However, some of the agglomeration of nanoparticles (may be due to presence of the capping agent) were also found (figure $4 \mathrm{c}$ ), and the surface was somewhat rough. It is noteworthy that the particles are non-uniformly mixed in a chitosan matrix.

The elemental composition of chitosan- $\mathrm{Ag}_{2} \mathrm{O}$ nanocomposite film was studied by energy dispersive analysis of $\mathrm{X}$-rays (EDAX). Figure 5 depicts the EDAX analysis from a selected area. The EDAX analysis confirmed that the nanocomposite structure contained about $4 \mathrm{wt} \% \mathrm{Ag}, 31 \mathrm{wt}$ $\%$ carbon, $7 \mathrm{wt} \%$ nitrogen, $28 \mathrm{wt} \%$ oxygen, $0.40 \mathrm{wt} \%$ sodium, and 27 wt $\% \mathrm{Au}$ (table 1). The presence of trace of Au was, however, also identified by EDAX analysis. We feel that this could be due to gold coating of nanocomposite film during the SEM analysis. The result corroborates the formation of chitosan- $\mathrm{Ag}_{2} \mathrm{O}$ nanocomposite film.

\subsection{Antimicrobial activity}

Various methods are employed to prepare antimicrobial chitosan films and coatings for food packaging applications. Solution casting method is one of the popular methods. As a general practice, chitosan films are prepared cross-linked by agylcone geniposidic acid (Mi et al 2006), ternary chitosan-glucomann-nisin (Li et al 2006), blending of ferulic acid incorporated starch-chitosan (Mathew and Abraham 2008), incorporation of garlic oil, potassium sorbate and nisin (Pranoto et al 2005). The derivatized chitosan such as O-carboxymethylated chitosan blended with cellulose from $\mathrm{LiCl} / \mathrm{N}, \mathrm{N}$-dimethylacetamide solution (Li et al 2002) has also been reported for antibacterial study. Most recently, Tripathi et al (2008a, 2009a,b, 2010) have synthesized chitosan based antimicrobial films for food applications employing supercritical carbon dioxide and microwave technique. The novelty of this method lies in achieving the film formation without addition of any cross-linker or plasticizer. The aim of the present work is to evaluate antibacterial activity of the nanocomposite film, so the antibacterial activity of the film and its solutions (1 and 2) against E. coli, B. subtilis, $P$. aeruginosa and $S$. aureus was measured by agar diffusion method. After $24 \mathrm{~h}$ incubation at $37{ }^{\circ} \mathrm{C}$, the chitosan-silver oxide nanocomposite film showed effective antibacterial effect on Gram-positive B. subtilis, S. aureus and Gram-negative E. coli and P. aeruginosa.

The ability of the film and its solution (1 and 2) to inhibit growth of the tested strains are listed in table 2 . The inhibitory activity was measured based on the diameter of the clear inhibition zone. If there was no clear zone surrounding, it was assumed that there was no inhibitory zone. Contact area was used to evaluate growth inhibition underneath 

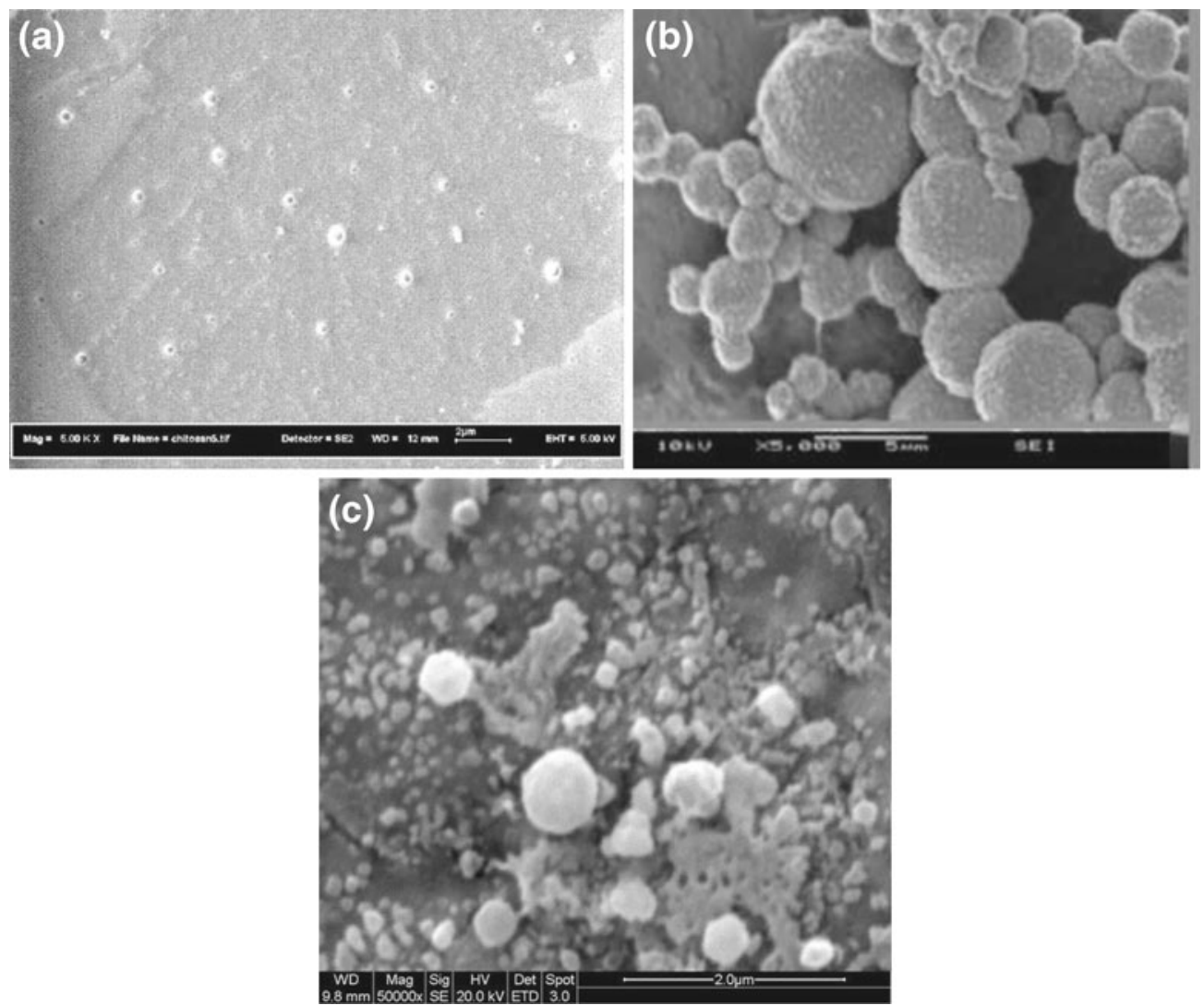

Figure 4. Scanning electron micrographs of chitosan, silver oxide and chitosan- $\mathrm{Ag}_{2} \mathrm{O}$ nanocomposite films (a), (b) and (c), respectively.

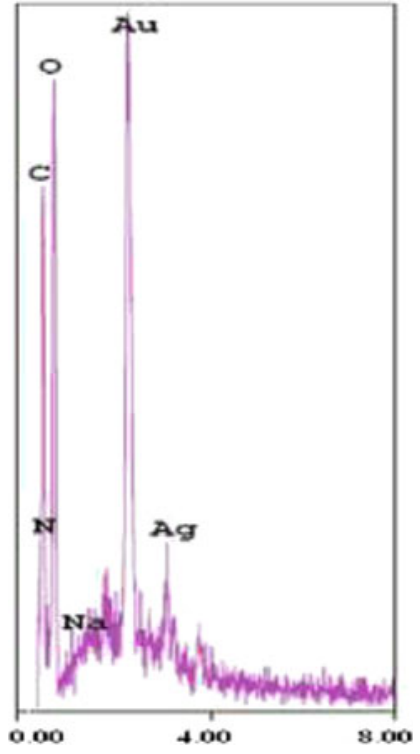

Figure 5. EDAX profile of chitosan silver oxide nanocomposite film. film discs in direct contact with target microorganisms in agar. In terms of surrounding clearing zone, the control chitosan film did not show inhibitory effect against all tested microorganisms.

The inhibitory zone of chitosan-silver oxide nanocomposite $\left(\mathrm{CS}-\mathrm{Ag}_{2} \mathrm{O}\right)$ film, its solutions 1 (diluted to $50 \%$ in aqueous $0.1 \%$ acetic acid), and 2 (as such) are shown in figure 6 . In terms of surrounding clearing zone, chitosansilver oxide nanocomposite film, its solutions (1 and 2) showed a very clear inhibitory effect against Gram positive

Table 1. Elemental composition of chitosan-silver oxide nanoparticles film.

\begin{tabular}{lc}
\hline Element & $\mathrm{Wt} \%$ \\
\hline $\mathrm{CK}$ & 31.59 \\
$\mathrm{NK}$ & 07.03 \\
$\mathrm{OK}$ & 28.93 \\
$\mathrm{NaK}$ & 00.40 \\
$\mathrm{AuM}$ & 27.43 \\
$\mathrm{AgL}$ & 04.62 \\
Total & 100.00 \\
\hline
\end{tabular}


and Gram negative bacteria. Our results have revealed that solutions 1 and 2 show very clear and greater inhibitory effect against $P$. aeruginosa, $S$. aureus, E. coli and B. subtilis in comparison to $\mathrm{CS}-\mathrm{Ag}_{2} \mathrm{O}$ nanocomposite film. One of the reasons for the antimicrobial character of chitosan is its positively charged amino group which interacts with negatively charged microbial cell membranes, leading to the leakage of proteinaceous and other intracellular constituents of the microorganisms (Shahidi et al 1999). In the Grampositive bacteria, the major constituent of its cell wall is peptidoglycan and there is very little protein. The cell wall of Gram-negative bacteria on the other hand is thinner but more complex and contains various polysaccharides, proteins and lipids beside peptidoglycan. The cell wall of Gram-negative bacteria also has an outer membrane, which constitutes the outer surface of the wall (Black 1996). Elemental silver has been believed to function antimicrobially either as a release system for silver ions or as a contact-active material (Chan et al 2004). In the present study, the chitosan nanocomposite films seem to be contact-active.

In general, chitosan film itself showed some antimicrobial effect even though it did not reveal inhibitory zone in any microorganisms tested. This is reasonable as chitosan has the innate characteristic of antimicrobial activity itself (Darmadji and Izumimoto 1994). According to Brody et al (2001), the antimicrobial effect of chitosan occurred without migration

Table 2. Antibacterial activities of film and solutions.

\begin{tabular}{lcccc}
\hline Sample CS-Ag $\mathrm{Ag}_{2} \mathrm{O}$ & \multicolumn{4}{c}{ Diameter (mm) of inhibitory zone against bacteria } \\
\cline { 2 - 5 } & E. coli & B. subtilis & P. aeruginosa & S. aureus \\
\hline Solution 1 & 14 & 19 & 22 & 22 \\
Solution 2 & 16 & 20 & 24 & 23 \\
Film disc $(d)$ & 10 & 10 & 13 & 14 \\
\hline
\end{tabular}
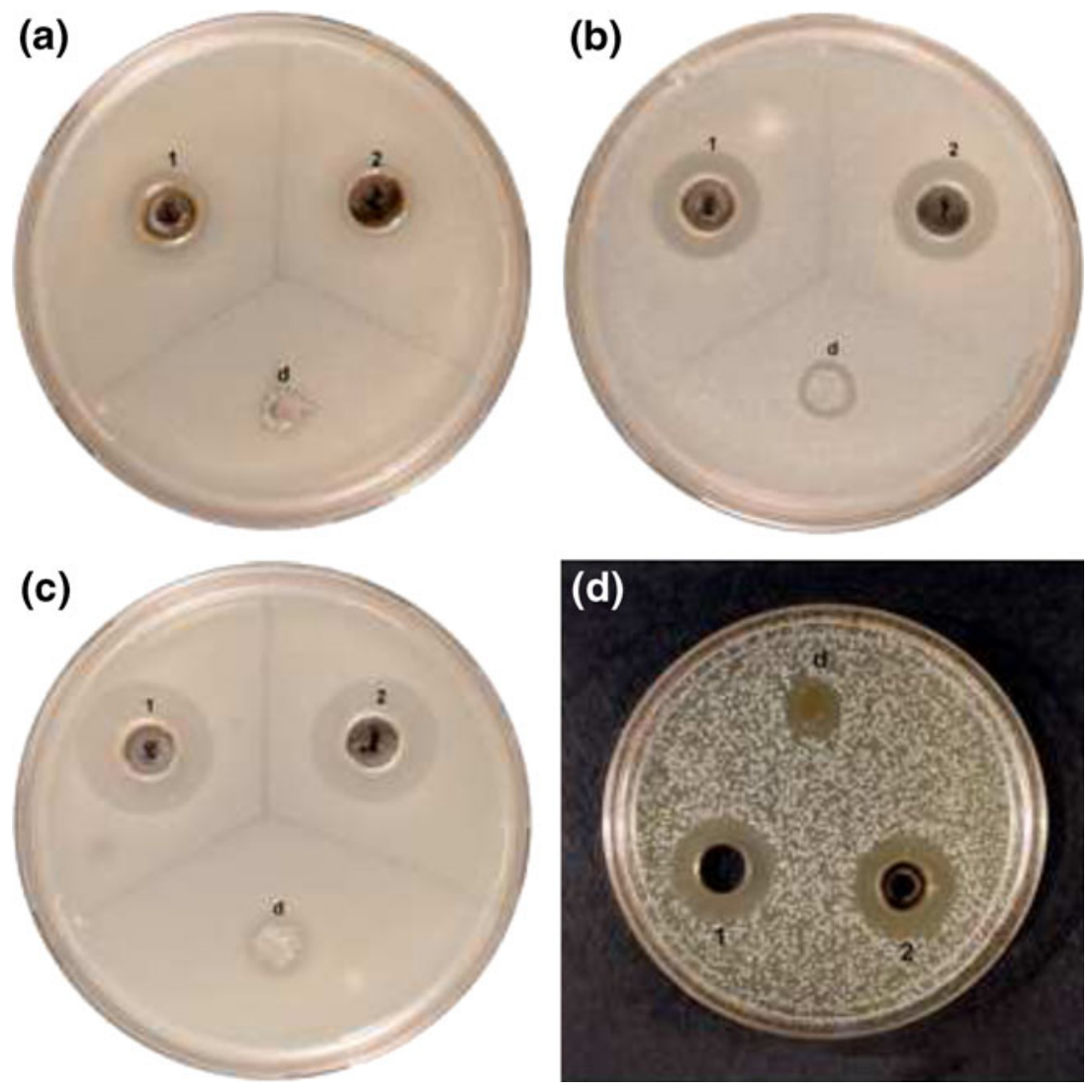

Figure 6. Inhibitory effect of chitosan-silver oxide nanocomposite film and solutions (1 and 2) against (a) E. coli, (b) B. subtilis, (c) P. aeruginosa, and (d) S. aureus. 
of active agents. As chitosan is in a solid form, therefore, only organisms in direct contact with the active sites of chitosan is inhibited. Chitosan is incapable to diffuse through the adjacent agar media (Coma et al 2002). The agar diffusion test is a method commonly used to examine antimicrobial activity regarding the diffusion of the compound tested through water-containing agar plate. The diffusion itself is dependent on the size, shape and polarity of the diffusing material. The chemical structure and the crosslinking level of the films also affect this phenomenon (Cagri et al 2001). When antimicrobial agents are incorporated, there will be diffusing materials through agar gel, and furthermore, resulting in clearing zone on the bacterial growth. Incorporating antimicrobial agents into chitosan edible film thus improves antimicrobial efficacy of chitosan, as diffused antimicrobial actively would add to non migrated antimicrobial potency of chitosan.

Chitosan has strong affinity towards metal ions because of the presence of numerous amine and hydroxyl groups (Varma et al 2004). Under alkaline condition chitosan can reduce $\mathrm{Ag}^{+}$ions to AgNPs (Murugadoss and Chattopadhyay 2008).

The outer membrane (OM) of Gram-negative bacteria such as E. coli consists of lipopolysaccharides (LPS) containing phosphate and pyrophosphate groups which render the cell surface negatively charged (Prescott et al 2002). As chitosan is a cationic polymer, it can attach to the $E$. coli cell wall by electrostatic interaction.

Below pH 6.5 chitosan can interact with the bacterial cell wall to destabilize it and alter cell permeability (Helander et al 1998, 2001). This process is probably enhanced by the binding of AgNPs to thiol-containing proteins present in the cell wall, with some of the AgNPs penetrating the cell wall to compromise permeability (Feng et al 2000; Gogoi et al 2006). This can lead to leakage of proteins and other intracellular constituents, and inactivation of the organisms (Helander et al 2001).

It has been proposed that AgNPs could interact with sulfur containing intracellular proteins in bacteria (Feng et al 2000). Further, chitosan has been studied in terms of bacteriostatic/bactericidal activity to control the growth of a wide variety of bacteria. Chitosan has several advantages over other types of disinfectants because, according to Kim and Choi (1998), it possesses a higher antibacterial activity and a broader spectrum of activity. The inhibitory activity of chitosan was observed on surface spoilage bacteria (Ouattara et al 2000a,b; No et al 2002; Savard et al 2002; Coma et al 2003; Gerasimenko et al 2004) and on various pathogen food strains (Siragusa and Dickson 1992; Helander et al 2001; Tsai and Su 1999; Tsai et al 2000; No et al 2002). The present investigation, therefore, indicates that the composite was efficient for inactivating bacteria, possibly due to synergistic effect of both the $\mathrm{Ag}_{2} \mathrm{O}$ nanoparticles and chitosan in the composite. The results suggest that the antimicrobial activity of chitosan can be enhanced with incorporation of silver oxide nanoparticles into chitosan film matrix as an easy processable technique for food packaging applications.

\section{Conclusions}

The chitosan-silver oxide nanocomposite film was prepared via solution casting method. The morphology of nanocomposite film was examined by SEM. The antibacterial effects of nanocomposite films against E. coli, B. subtilis, P. aeruginosa and $S$. aureus were examined by agar diffusion method. The results reveal a nanoparticle formation within the chitosan matrix. It was proved that the nanosilver containing chitosan film had an excellent antibacterial performance. Typically, the nanocomposite film may be used to wrap foods that are highly susceptible to microbial growth or directly used as a surface coating on perishable fruits and vegetables to enhance microbial safety and extend food shelf life.

\section{Acknowledgements}

The authors wish to thank the Director, Motilal Nehru National Institute of Technology, Allahabad, for providing a Institute Research Fellowship to (ST) and UGC and CSIR, New Delhi, for research project grants to (PKD). Authors also like to thank SAIF, Kochi, for providing the EDAX, TGA and SEM facilities.

\section{References}

Ahmad Z, Pandey R, Sharma S and Khuller G K 2006 Indian J. Chest Dis. Allied Sci. 48171

Black J G 1996 Microbiology: principles and application (New Jersey: Prentice-Hall, Inc.) pp. 80-82

Brody A L, Strupinsky E R and Kline L R 2001 Active packaging for food applications (Lancaster: Technomic Publishing, Inc.) p. 218

Cagri A, Ustunol Z and Ryser E T 2001 J. Food Sci. 66865

Chan H H, Jan T, Christina S, Ralf T and Joerg C T 2004 Adv. Mater. 16967

Coma V, Martial-Gros A, Garreau S, Copinet A and Deschamps A 2002 J. Food Sci. 671162

Coma V, Deschamps A and Martial-Gros A 2003 J. Food Sci. 68 2788

Darmadji P and Izumimoto M 1994 Meat Sci. 38243

Dolgaev S I, Simakin A V, Voronov V V, Shafeev G A and BozonVerduraz F 2002 Appl. Surf. Sci. 186546

Dutta P K, Dutta J, Chattopadhyaya M C and Tripathi V S 2004 J. Polym. Mater. 21321

Dutta P K, Tripathi S, Mehrotra G K and Dutta J 2009 Food Chem. 1141173

Feng Q L, Wu J, Chen G Q, Cui F Z, Kim T N and Kim J O 2000 J. Biomed. Mater. Res. 52662

Friedman M and Juneja V K 2010 J. Food Prot. 731737

Gerasimenko D V, Avdienko I D, Bannikova G E, Zueva O Yu and Varlamov V P 2004 Appl. Biochem. Microbiol. 40253

Gogoi S K, Gopinath P, Paul A, Ramesh A, Ghosh S S and Chattopadhyay A 2006 Langmuir 229322

Gong P, Li H, He X, Wang K, Hu J, Tan W, Zhang S and Yang X 2007 Nanotechnology 18604

Gu H, Ho P L, Tong E, Wang L and Xu B 2003 Nano Lett. 31261 
Helander I M, Latva-Kala K and Lounatmaa K 1998 Microbiology 144385

Helander I M, Nurmiaho-Lassila E L, Ahvenainen R, Rhoades J and Roller S 2001 Int. J. Food Microbiol. 71235

Hernández-Lauzardo A N, Bautista-Baños S, Velázquez-del Valle M G, Méndez-Montealvo M G, Sánchez-Rivera M M and BelloPérez L A 2008 Carbohyd. Polym. 73541

Herrera M, Carrion P, Baca P, Liebana J and Castillo A 2001 Microbios 104141

Jin Y D and Dong S J 2003 J. Phys. Chem. B107 12902

Kim C and Choi K S 1998 J. Ind. Eng. Chem. 419

Li B, Kennedy J F, Peng J L, Yie X and Xie B J 2006 Carbohyd. Polym. 65488

Li Z, Zhuang X P, Liu X F, Guan Y L and Yao K D 2002 Polymer 431541

Mathew S and Abraham T E 2008 Food Hydrocolloids 22826

Mi F-L et al 2006 J. Agr. Food Chem. 543290

Murugadoss A and Chattopadhyay A 2008 Nanotechnology 19 015603/1

Nigam N, Kumar S, Dutta P K and Ghosh T 2009 Asian Chitin J. 5 97

No H K, Park N Y, Lee S H and Meyers S P 2002 Int. J. Food Microbiol. 7465

Nonaka T, Noda E and Kurihara S 2000 J. Appl. Polym. Sci. 771077

Ouattara B, Simard R E, Piette G, Begin A and Holley R A 2000a J. Food Sci. $\mathbf{6 5} 768$

Ouattara B, Simard R E, Piette G, Begin A and Holley R A 2000b Int. J. Food Microbiol. 62139

Pranoto Y, Rakshit S K and Salokhe V M 2005 Lebensm. Wiss. Technol. 38859

Prescott L M, Harley J P and Klein D A 2002 Microbiology (New York: The McGraw-Hill Companies) 5th ed. pp. 46
Retchkiman-Schabes P S, Canizal G, Becerra-Herrera R, Zorrilla C, Liu H B and Ascencio J A 2006 Opt. Mater. 2995

Salleh E, Muhamad I and Khairuddin N 2007 Asian Chitin J. 355

Savard T, Beauliu C, Boucher I and Champagne C P 2002 J. Food Protection $\mathbf{6 5} 828$

Schierholz J M, Beuth J and Pulverer G 1999 Am. J. Med. 107 101

Shahidi F, Arachchi J K V and Jeon Y J 1999 Trends Food Sci. Technol. 1037

Siragusa G R and Dickson J S 1992 J. Food Sci. 57293

Spadaro J A, Berger T J, Barranco S D, Chapin S E and Becker R O 1974 Antimicrob. Agents Ch. 6637

Tripathi S, Mehrotra G K and Dutta P K 2008a e-Polymers 0931

Tripathi S, Mehrotra G K, Tripathi C K M, Banerjee B, Joshi A K and Dutta P K 2008b Asian Chitin J. 429

Tripathi S, Mehrotra G K and Dutta P K 2009a Int. J. Biol. Macromol. 45372

Tripathi S, Mehrotra G K and Dutta P K 2009b Advances in chemical engineering (New Delhi: Macmillan Publishers India Ltd.) p. 69

Tripathi S, Mehrotra G K and Dutta P K 2010 National seminar on contemporary research in material science and chemical biology (Allahabad: University of Allahabad)

Tsai G J and Su W H 1999 J. Food Protection 62239

Tsai G J, Wu Z Y and Su W H 2000 J. Food Protection 63747

Turker M 2004 Mater. Sci. Eng. A367 74

Varma A J, Deshpande S V and Kennedy J F 2004 Carbohyd. Polym. $\mathbf{5 5} 77$

Yoshida K, Tanagawa M and Atsuta M 1999 J. Biomed. Mater. Res. 47516

Zhao G J and Stevens S E 1998 Biomaterials 1127 